\title{
Student Centred Learning Using Student's Learning Style
}

Pratik R. Kadam ${ }^{1}$, Umesh K. Gaikwad ${ }^{2}$, Preeti D. Bhamre ${ }^{3}$

${ }_{1,2,3}$ Department of Information Technology, K.. K.. Wagh Institute of Engineering Education and Research, Nashik

1pr.kadam@kkwagh.edu.in,

2ukgaikwad@kkwagh.edu.in,

3 pdbhamre@kkwagh.edu.in

\begin{abstract}
Traditional and modern teaching methodologies focus less on the learning style of a student. In countries like India, the average strength of the class is 60 and it becomes very difficult to focus on each student individually. Instead of being student centric, the current engineering education system is more teacher-centric. It is inappropriate to assume that the same learning methodology is applicable to all students. There should be an attempt to customize the lecture delivery method or teaching style suitable to address heterogeneous learners in the classroom. This study explores how one can use some part of cognitive psychology to determine the learner bias i.e. learning styles of each student which can be used in customizing the delivery of subject to make it more student centric. In this proposed methodology visual, auditory and kinaesthetic (VAK) Model is used to determine learning style of the students. Depending upon the learning style of students, teacher modifies the classroom delivery methodology. Students are also provided learning resources and assignments based on their learning style. This approach is being tested on three different subjects of same class of second year engineering student of Information Technology. The test results post learning style methodology implementation are compared with earlier results for comparison. It has been observed that there is a notable improvement in the overall learning of each student. The implementation of student centred learning when aligned with the learning style of students can create a great impact on student's performance.
\end{abstract}

\section{Keywords:}

VAK model, learning styles, heterogeneous learner, learning models

\section{Introduction}

India as per 'Science and Engineering Indicators 2020 report' ranks \#1 in producing engineering and science graduates. The All India Survey on Higher Education (AISHE) 2019 report by the Ministry of Human Resources states that $80 \%$ of Indian engineers are unemployed.

\section{Pratik R. Kadam}

IT Dept, K. K. Wagh Institute of Engg. Education \& Research, Panchwati, Amruthdham, Nashik, Maharashtra, India. 422003

pr.kadam@kkwagh.edu.in

These two reports highlight the two opposite sides of the Indian engineering education system. Efforts have been made to make engineering education fun by adopting new teaching methodologies like collaborative learning, flipped learning, etc. Even then the expected outcome is not achieved. The problem is not with the syllabus, faculty, students or infrastructure in many engineering educational institutes but it is with the heterogeneous learners in the classroom. Indian engineering education institutes get students admitted from various geographical locations with great diversity in their attitude, aptitude, intelligence, interest, personality, etc. Apart from all the above mention diversities, an important aspect that plays a pivotal role in their overall learning of any student is his/her learning style. A learning style is a student's consistent way of responding to and using stimuli in the context of learning. Learning style is predominantly classified into three parts visual, auditory and kinesthetic. Visual learners prefer diagrams and spatial understanding. Auditory learners prefer usage of sound, music and verbal explanation to learn new things. Kinesthetic learners prefer body, hand and sense of touch.

On the other side, it is observed that most engineering teachers deliver the lecture in the classroom according to their own comfort zone, thus making the current engineering education more teacher-centric instead of student centric. Though teachers are putting so many efforts to enhance their teaching by using ICT tools and innovative teaching methodologies, it is still not creating an impact on student's learning. The probable reason could be that of inadequate attention and addressing towards student's learning style. This creates a huge gap between the expected learning outcome and actual learning outcome of the course. To bridge this gap it is very important that teacher understands the students learning style and teach the way student understands. Every individual is different and so are the students. Every student has different way to acquire new information which will influence the type of presentation or activity that best transfers the knowledge to him. Understanding learning style will help teacher plan their lecture as per the student's learning preference. In the proposed study the learning style of students is identified using VAK Model. The results are used to customize the lecture delivery to cater the student's learning styles. The aim of this study is to verify whether students achieve greater learning outcomes when they are taught and given activities based on their learning style.

\section{Literature Survey}

\section{A. Learning Styles and Models}

Learning style is indicator which shows how each individual grasps, processes, comprehends and memorizes 
the information. Individual learning style is dependent on various factors like intellectual, physical, emotional, social, mental, environmental and cultural factors. Many educationists have already done tremendous work to understand the learning preferences of individual student. It has been observed that we can teach in better way if we know the learning style of the learner in advance.

Researchers have already identified various categories of the learner, in which visual and auditory learners form two major groups globally. Visual learners can grasp the information quickly by using pictures, diagrams, flow charts, time lines, films, demonstrations. Most of the students belong to this wide category of learners. While the auditory learners get the things through verbal discussion, listening to anyone or repeating \& explaining the things to other (Felder, 1988) (Raiyn 2016).

Another major category is that of kinaesthetic or tactile learners. Kinaesthetic learning consists of both information perception as well as information processing. In information processing learner learns through activities like touching, tasting, smelling while in Information processing learner learns through moving, relating, doing something active while learning. These characteristics of learner are best suited for the engineering education (Felder, 1988) (Tyas, 2017). One more learning style is Inductive learning which is based on the observation ability of the learner. Small babies tend to learn many things from scratch just by observations. In deductive learning, learner initially understands the concept, law, rule and then practice it through various activities (Prince, 2006).

In Active and Reflective Learners group, Active learner is habitual to understand the things by doing a related activity like discussing or applying it, explaining it to others etc. Whereas reflective learner learns the things by examining or analysing the scene introspectively. Active learners have more extrovert personality (Felder,1988) (McCoy,2013). Based on the ability of learner to understand the bigger picture and problem, Felder has described sequential learner and global learner group (Felder,1988). Sequential learners learn best by understanding the details of a subject and slowly building an image of the bigger picture. Sequential learners work very well with details but often have trouble understanding larger concepts and ideas. Global learners need to see the bigger picture and how the new material connects to information they have already learned. Global learners work well with larger concepts or ideas but struggle with the details.(Felder,1988) Based on the learning styles various assessment modelare also devised. One of the initial models was suggested by the David Kolb's in which a group of 4 categories of the learners was formed, Accommodator, Converger, Diverger \& Assimilator (Kolb,1984). Peter Honey and Alan Mumford's have used Kolb's experiential learning model and based on that learning styles are categorized in 4 different groups - Activist, Reflector, Theorist \& Pragmatist (Mumford,1997).

One of the major contributions in this domain is by Barbe and then Fleming through VAK and VARK Model (Barbe,1979) (Fleming,1995). In VAK model Barbe has created set of three learning styles Visual, Auditory and Kinesthetic. Grasha \& Reichmann formulated the new set of the learning style under the name Cognitive Model in which he made group of six different learning styles avoidant, participative, competitive, collaborative, dependent \& independent (Riechmann,1974).

\section{B. Learning style of Engineering Students}

Undergraduate students in engineering are mainly pure kinesthetic learners and multimodal learners with a high preference for kinesthetic input (Driscoll,2000). Most engineering students are visual, sensing, inductive and active. It is found that most creative students are global (Devrim,2011). The sample respondents have shown that approximately $25 \%$ of students prefer a multi-modal learning style within the classroom. This is followed by the kinesthetic style requiring continuous practice to enhance knowledge of the subject. Engineering students can learn best by experimentation and by focusing on specific problem statement.

\section{Framework of the Research Study}

Students learn best by looking at the value and information provided to them during lectures. If students cannot connect themselves with the material and information given to them during the lecture then they will not learn it. Learning style of the student is the key element which helps a faculty to connect with students during the lectures and achieve better learning experience. In the present study as per the VAK model, learner styles are mainly classified as visual, auditory and kinaesthetic. The definition of these learner styles is as follows:

Visual: Visual learners think about pictures and grasp best from visual images. They also depend on the instructor's or facilitator's non-verbal cues such as body language to help with understanding a concept. Sometimes, visual learners favour sitting in the front of the classroom. They also take descriptive notes over the material being presented (Fleming 1995).

Auditory: These learners discover information through listening and interpreting information by the means of pitch emphasis and speed. These individuals gain knowledge from reading out loud in the classroom and may not have a full understanding of information that is written (Fleming, 1995).

Kinaesthetic: The learners that are kinaesthetic learn best with and active "hands-on" approach. These learners favour interaction with the physical world. Most of the time kinaesthetic learners have a difficult time staying on target and can become unfocused effortlessly (Fleming,1995).

The teacher is still the most important person to achieve this overall learning as teacher needs to customize his lecture as per heterogeneity of learners in the classroom. The proposed framework works as follows:

1. Identification of student's learner style in a chosen class.

2. Planning of lecture delivery.

3. Lecture Conduction. 
4. Sharing learning resources and task to individual student based on his/her learning style.

5. Continuous Assessment during learning.

\section{A. Identification of Student's Learner Style:}

To identify the learner style of each student has been used Visual, Auditory and Kinaesthetic (VAK) Model. These are multi-sensory learning styles that involve three elements of learning style: sight, hearing, and movement. VAK model was designed by Walter Burke Barbe and later developed by Niel Fleming. To identify the learner style as per the VAK model, a questionnaire of 30 most relevant questions has been designed and made publicly available by Walter Burke. After seeking consent of the students, these 30 questions were asked to students. Depending upon the responses students were categorized into four group's i.e visual group, auditory group, kinaesthetic group and Multimodal group. Multimodal group consists of the students whose results showed that they are not typically inclined towards any particular learning style. Every student was made aware about his/her learning style and is conveyed about how he/she should focus on his/her learning style to gain maximum knowledge in his/her life.

\section{B. Planning of lecture delivery}

Depending upon the results from the earlier step, the teacher needs to design a customized lecture plan. The lecture plan should be designed in such a way that it addresses all learner styles. The lecture should not be completely pictorial or completely talking. It should contain a mix of images, speech and problem solving to cater the need of all three basic learners. If the results show that majority of the learners in the class are of specific learning style then major focus while planning the lecture should be on those learners.

Table 1: Online Tools

\begin{tabular}{|l|l|l|}
\hline Visual & Auditory & Kinesthetic \\
\hline MindMeister & Free Audio Books & $\begin{array}{l}\text { Student } \\
\text { Interactives }\end{array}$ \\
\hline Visuwords & Audacity & ClassMarker \\
\hline MylearningTube & PodOmatic & Quizlet \\
\hline TeacherTube & Midomi & NoteMesh \\
\hline Pics4Learning & ReadPlease & Cram \\
\hline \multicolumn{1}{|l|}{ Table 2: Teaching Aids } \\
\hline Visual & NaturalReader & Google Sketchup \\
\hline Miming & Audio aids & Kinesthetic \\
\hline Puppets & Using Rhymes & Solving puzzles \\
\hline Flashcards & Loud Recitation & Notes/Summary \\
\hline Videos & Presenting in class & Clay Modelling \\
\hline Pictures & Using different & $\begin{array}{l}\text { PPT/Poster } \\
\text { voices }\end{array}$ \\
\cline { 1 - 1 } & & Making \\
\cline { 1 - 1 } Maps & & Field Visits \\
\hline Mind Maps & & Role Playing \\
\hline Concept Maps & & $\begin{array}{l}\text { Conducting } \\
\text { Experiments }\end{array}$ \\
\hline
\end{tabular}

The Table $1 \& 2$ lists different online tools \& teaching aids that can be used by teachers if these tools are suitable for teaching their subject. Teacher can either use them in the classroom teaching or can use them in assigning tasks to respective learners.

\section{Lecture Conduction}

Teacher starts the lecture by connecting with students by addressing the topic considering all learning styles. Lecture is delivered as per the lecture planning done in the earlier step. As teacher is aware of learning style of each student, teacher randomly asks questions or give activity to the students based on his/her learner styles.

\section{Sharing learning resources}

After the lecture or after completion of certain topic, a learning material is shared with the students. This learning material were different for each learner group identified in the step 1. Small tasks are also given with this learning material and those tasks would also be different based on the student's learning style. This heterogeneous learning material and task on heterogeneous learners helps in connecting with student and students also love to do task which suits their learning style. For example, visual learner prefers learning an algorithm by visualizing it in terms of flow chart while kinaesthetic prefers learning an algorithm by debugging algorithm by passing some input to that algorithm.

\section{E. Continuous Assessment}

Assessment is the most important step of this process as it validates whether students learning has enhanced and to what level. The assessment in terms of MCQ's at the end of the lecture to check the overall learning of the students was conducted. Teacher should also give some assignments which addresses the higher levels of bloom's taxonomy. The flow of the proposed model is shown in the figure 1 .

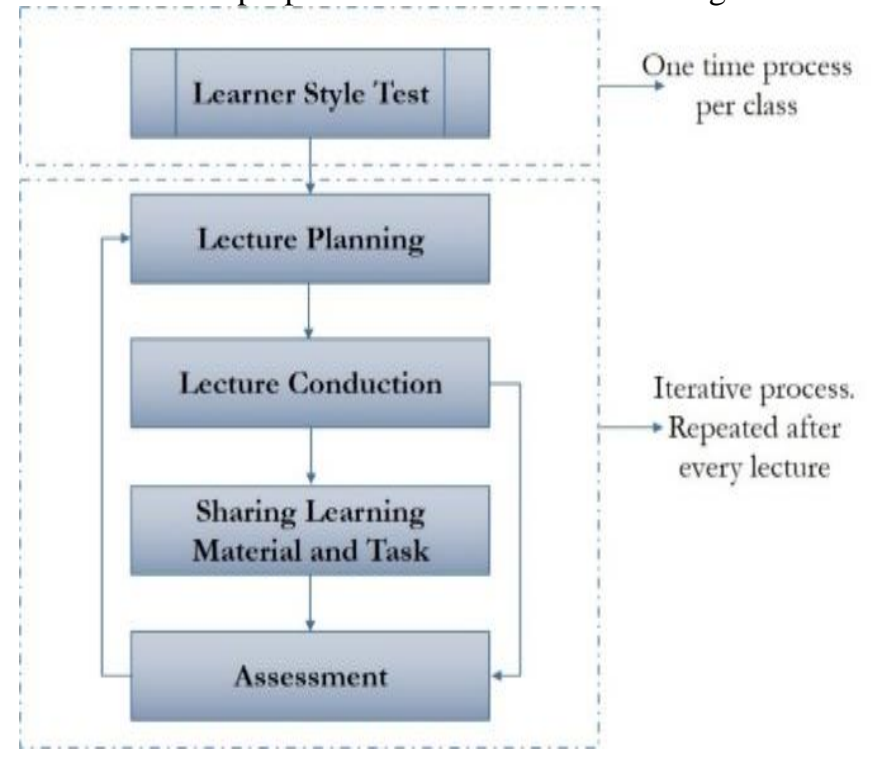

Figure 1: Workflow of proposed model 


\section{Experiment and Results}

As per the proposed methodology, before starting the experimentation, consent was taken from all learners. All students who had given consent were asked to give learner style test based on VAK Model. Total 60 learners had undergone through the evaluation. After the test it was found that 4 types of learners were present in the group i.e. visual, auditory, kinaesthetic and multimodal. The distribution of learners as per their style is as shown in figure 2.

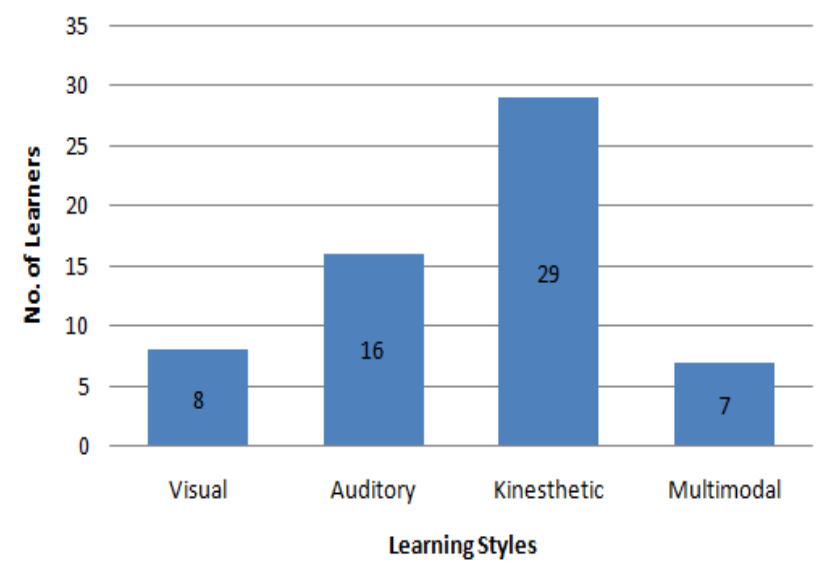

Figure 2: Learners Distribution

After identification of the learner's style, three pre-tests were conducted for the subjects Discrete Mathematics, Object Oriented Programming and Computer Organization \& Logic Design. After conducting the pre-test, a different set of study material was shared for each subject as per the learner's style of the student. The learners were given sufficient time to study and complete the task given to them. Again post-test was conducted for all the three subjects to check the effectiveness of the proposed model. Both pretest and post-test has questions with varying complexity. It is also observed that perofrmance of learners from all category is improved in the subject Discrete mathematics and Object Oriented programming as shown in figure 3 and 4.

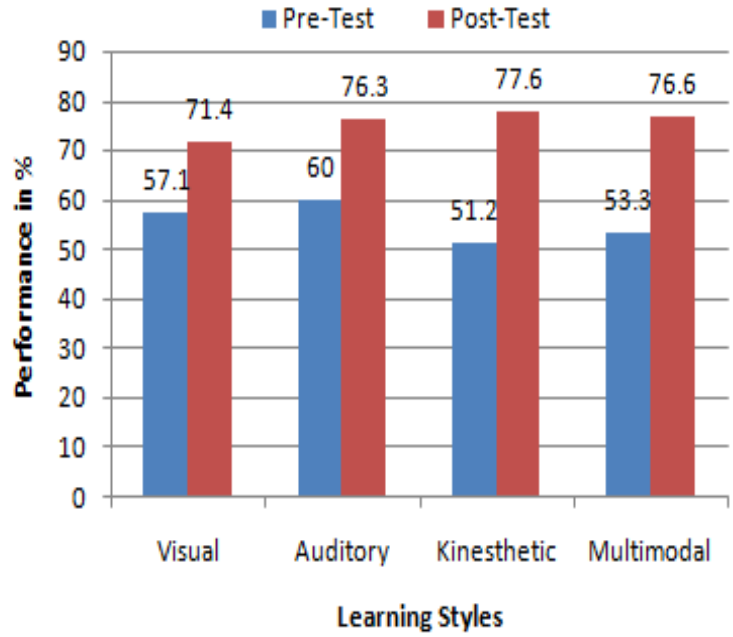

Figure 3: Learner's performance in the subject Discrete Mathematics

As shown in figure 5, in the subject Computer Organization \& Logic Design Performance of the learner from Visual and Multimodal Category is improved while it is slightly decreased for Auditory and Kinaesthetic group. It indicates that for the said subject needs more focus on these two learner groups.

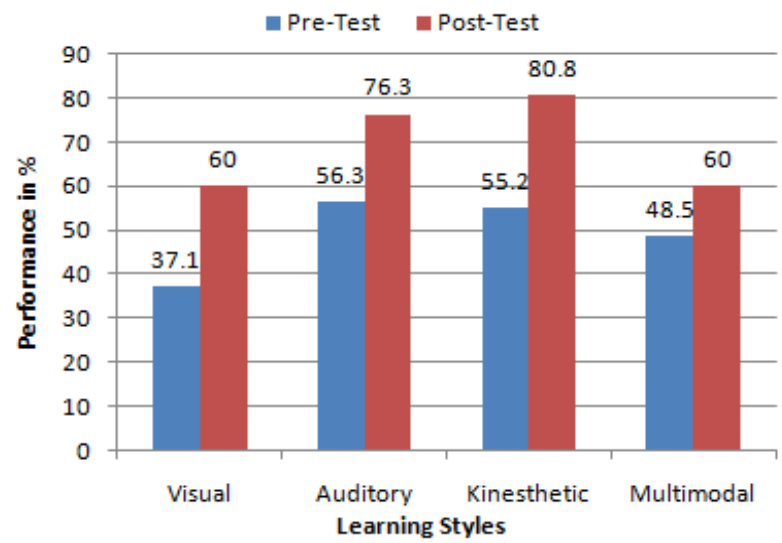

Figure 4: Learner's performance in the subject Object Oriented Programming

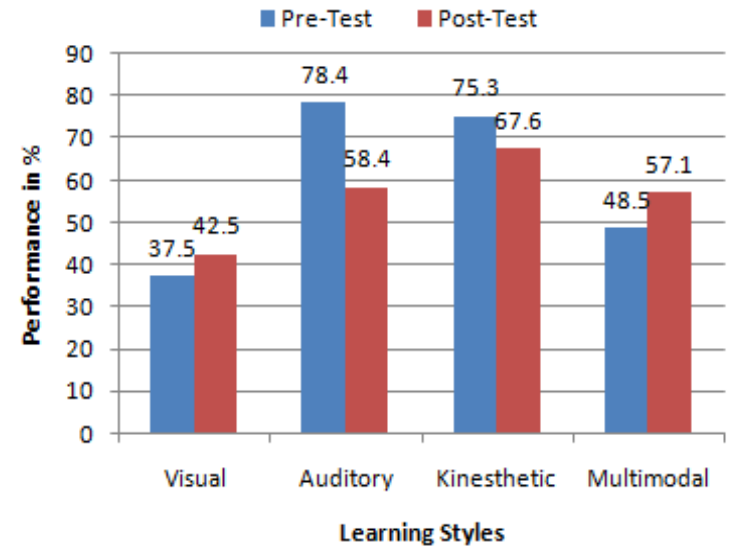


Figure 5: Learner's performance in the subject Computer Organization \& Logic Design

Figure 6 illustrates average performance for each category of the learners in the both the tests. It is also observed that average performance of each Learners category get improved significantly. It can be seen that after applying our proposed methodology, the overall performance is improved by $10 \%$.

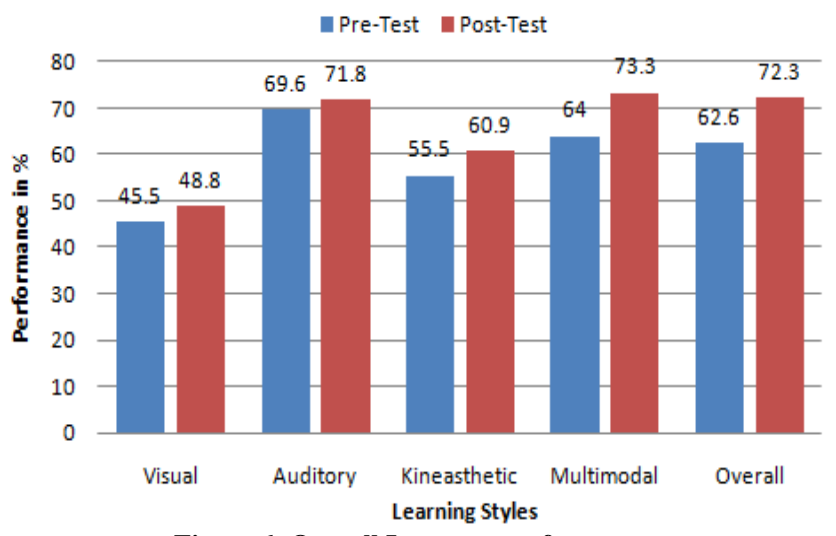

Figure 6: Overall Learners performance

\section{Conclusion}

A student centred learning methodology based on student's learning style is implemented. The VAK Model results show that most preferred learning style of student is kinaesthetic, then auditory and visual. It is observed that the overall performance of students was raised by $10 \%$ which is significant in the first attempt. The subject wise results show that there is major improvement in student's performance in two subjects as compared to the subject. Other observations also show that there is improvement in the each learner group with major improvements in kinaesthetic and multimodal learners. Thus with these results one can conclude that by orienting teaching and related activities with respect to the learning styles of students in teaching benefits both students and teachers. Teachers should plan and conduct the lectures considering the heterogeneous learners in the class to enhance the learning experience of the students. This student centred learning approach will make lectures more interesting for the students as they will be able to perceive more knowledge.

\section{Reference:}

[1] Richard M. Felder, 1988, "Learning and Teaching Styles in Engineering Education", Journal of Engineering Education 78(7):674-681

[2] Jamal Raiyn, 2016, "The Role of Visual Learning in Improving Students' High-Order Thinking Skills", Journal of Education and Practice www.iiste.org ISSN 2222-1735 (Paper) ISSN 2222-288X (Online) Vol.7, No.24, 2016

[3] Peptia Asrining Tyas , Mega Safitri, 2017, "Kinesthetic Learning Style Preferences: A Survey of Indonesian EFL Learners by Gender", JEES (Journal of English Educators Society), 2(1):53 DOI: 10.21070/jees.v2i1.688
[4] Michael Joseph Prince, Richard M. Felder, 2006, "Inductive Teaching and Learning Methods: Definitions, Comparisons, and Research Bases", Journal of Engineering Education, 95:123-137,DOI: 10.1002/j.2168-

9830.2006.tb00884.x

[5] Bryan McCoy, 2013, "Active and Reflective Learning to Engage All Students", Universal Journal of Educational Research1 (3): 146-153, DOI: 10.13189/ujer.2013.010302

[6] Kolb, David A., 1984, "Experiential learning: experience as the source of learning and development", 2nd Edition, ISBN 9780133892406, Pearson Education

[7] Mumford, Alan, 1997, "Putting learning styles to work, Action learning at work", ISBN 0566078902, Alder shot, Hampshire; Brookfield, VT: Gower. pp. 121-135

[8] Barbe, Walter Burke, Swassing, Raymond H., Milone, Michael N. (1979). Teaching through modality strengths: concepts and practices. Columbus, Ohio: Zaner-Bloser [9] Fleming, Neil D., 1995, "I'm different; not dumb: modes of presentation (VARK) in the tertiary classroom", Proceedings of the 1995 Annual Conference of the Higher Education and Research Development Society of Australasia (HERDSA),HERDSA, Volume 18, pp. 308 313

[10] Riechmann, Sheryl Wetter; Grasha, Anthony F., 1974, "A rational approach to developing and assessing the construct validity of a student learning style scales instrument", The Journal of Psychology. 87 (2): 213-223. doi:10.1080/00223980.1974.9915693

[11] S. A. Driscoll, C. E. Garcia, 2000, "Preferred learning styles for engineering students," (St. Louis, MO, United states), pp. 4801-4810

[12] Burcu Devrim , Hande Eryilmazb, 2011, "Determining Learning Styles of Engineering Students to Improve the Design of a Service Course", Procedia - Social and Behavioral Sciences 28, 342 - 346

[13] Askar, P. \& Akkoyunlu, B. (1993). Kolb learning style inventory, Education and Science, 15(81), 37-47 